\title{
Drugs, alcohol and sexual health: opportunities to influence risk behaviour
} Robert Patton*1, Francis Keaney ${ }^{1}$ and Michael Brady ${ }^{2}$

\author{
Address: ${ }^{1}$ National Addiction Centre, Institute of Psychiatry, Kings College London, UK and ${ }^{2}$ Kings College Hospital NHS Foundation Trust, \\ Denmark Hill, London, UK \\ Email: Robert Patton* - r.patton@iop.kcl.ac.uk; Francis Keaney - f.keaney@iop.kcl.ac.uk; Michael Brady - michael.brady@kch.nhs.uk \\ * Corresponding author
}

Published: 18 June 2008

BMC Research Notes 2008, 1:27 doi:10.1 I86/1756-0500-1-27

This article is available from: http://www.biomedcentral.com/I756-0500/I/27

(c) 2008 Patton et al; licensee BioMed Central Ltd.

This is an Open Access article distributed under the terms of the Creative Commons Attribution License (http://creativecommons.org/licenses/by/2.0), which permits unrestricted use, distribution, and reproduction in any medium, provided the original work is properly cited.
Received: II March 2008

Accepted: 18 June 2008

\begin{abstract}
Background: Alcohol and drug consumption can affect judgment and may contribute towards an increased likelihood of engaging in risky sexual behaviour. In this cross sectional survey of clients attending STI services levels of drug and alcohol use were assessed using two standardised drug and alcohol screening instruments (the PAT and the SDS).

Findings: The rates of hazardous alcohol consumption were similar to those found among patients attending A\&E departments. Approximately $15 \%$ of clients indicated possible dependence on alcohol or other drugs, and these clients were likely to cite their substance use as related to their attendance, and to accept the offer of help or advice.

Conclusion: The use of brief screening instruments as part of routine clinical practice is recommended. The STI clinic is well placed to identify substance use and to offer advice and/or onward referral to specialist services.
\end{abstract}

\section{Introduction}

Research examining the prevalence of Sexually Transmitted Infections (STI) and risk behaviours amongst a population of drug users in treatment indicates a high level of unprotected sexual activity [1] (22\%). Hwang et al [2] found that $62 \%$ of drug users in treatment had serological markers for at least one STI. Another study by Lally et al [3] indicated that $23 \%$ of women in short-term substance abuse treatment were infected. A review by Marx et al (1991) [4] found associations between drug use (particularly crack) and STIs.

High rates of hazardous drinking among clients were confirmed during a recent pilot study based in the sexual health clinic at St Mary's Hospital in inner-London [5], in this study 96 patients attending a walk-in clinic were screened, $27 \%$ were found to be drinking excessively and $13 \%$ thought their attendance in the clinic might be related to their consumption of alcohol. The relationship between drug taking and engagement in sexual activity (protected or unprotected) is important; however the establishment of a causal relationship between the two remains unproven [6]. STI services offer an opportunity to identify hazardous and harmful drug and alcohol users and to either offer them brief advice in the form of a leaflet, or refer them on to specialist services. This study examines the prevalence of substance use among clinic users, their perception as to the relationship between their substance use and clinic attendance and the extent to which they are willing to accept help and advice about their drug or alcohol usage. 


\section{Method}

Over a six week period, 700 consecutive clients attending an STI clinic of a busy South London hospital were approached by a junior doctor. At the end of the consultation, having obtained consent, the doctor administered the Brief Alcohol \& Drug Screen; a composite measure that includes the Paddington Alcohol Test (PAT) [7] and Severity of Dependence Scale (SDS) [8,9]. Participants who indicated that they drank more than 8 (male) or 6 units (female) on a single occasion, or who admitted that their visit to the clinic was related to their drinking, were classified as hazardous drinkers. Those scoring $3+$ on the SDS were regarded as possibly dependant. Participants identified as hazardous drug or alcohol users were offered a leaflet outlining how they could access help with their substance use problem, and asked if a referral were made to local drug/alcohol services whether they would attend.

\section{Results}

Six hundred and fifty three clients consented to participate in the study (93\%). The majority were male (59.4\%). Participants were aged between 17 and 78, with most in the 25-44 age group (55.5\%). The majority of clients drank alcohol $(71 \%)$, with $28.2 \%$ identified as hazardous drinkers $339.5 \%$ of those who drank alcohol were hazardous drinkers). $13.8 \%$ of the sample smoked tobacco. Illicit substance use was not widespread among participants, with just $5.3 \%$ admitting cannabis use, and less than $0.5 \%$ other drugs. Almost a quarter of all hazardous alcohol users (and $14.7 \%$ of all participants overall) were SDS positive, indicating possible dependence. Table 1 indicates the proportion of Alcohol, Tobacco and Cannabis users who were SDS positive, who accepted the offer of help and who indicated willingness to attend a referral.

One in seven hazardous drinkers (14.2\%) and half of those identified as SDS positive accepted an offer of help or advice, and of these $90 \%$ indicated that they would also accept a referral for an appointment with a specialist to discuss their alcohol or drug consumption.

Overall $6.6 \%$ of the sample thought that their attendance was related to their substance use. Binary logistic regression indicated that hazardous drinking did not predict the acceptance an offer of help/advice (OR 0.5, 95\% CI 0.3 0.9), however SDS+ status did (OR 17.2, 95\% CI 9.0 -
32.3). SDS+ status also predicted patients who indicated that their attendance was related to their substance use (OR 3.1, 95\% CI 1.5 - 6.5).

\section{Discussion}

Clinicians may be surprised at the low numbers of clients who related their attendance to substance use; however this might be expected, given that in other settings, such as Accident \& Emergency departments, rates are similar [8].

The 2000 Psychiatric Morbidity Survey [11] reports hazardous alcohol consumption, tobacco and cannabis use in the UK general population to be $26 \%, 30 \%$ and $25 \%$ respectively. Participants in the study had similar rates of hazardous alcohol use, but much reduced rates of both tobacco and cannabis consumption. Interestingly, the rate of possible dependence to alcohol was six times the national rate $(24.6 \%$ vs. $4 \%)$. These results suggest that harmful levels of alcohol consumption are associated with STI clinic attendance, and future research should attempt to determine if there is a causal relationship.

STI clinics are well placed both to identify substance use and to offer onward referral to those whose use is problematic. At present most STI services do not routinely screen for alcohol or other drugs. The identification and appropriate referral of those clients whose substance use may well be associated with their clinic attendance may not only help to reduce clinic workload, but also enable STI services to deliver an important public health message.

This study indicates that using a brief screening instrument for drugs and alcohol as part of routine clinical work is a feasible proposition. While clinicians may be reluctant to address issues of substance misuse in the clinic setting, many clients are certainly receptive to advice and onward referral, which we know will help reduce their consumption and may in turn reduce the likelihood of engaging in risk behaviours.

\section{Competing interests}

The authors declare that they have no competing interests.

Table I: Alcohol, tobacco and cannabis consumption

\begin{tabular}{lccccc}
\hline & $\begin{array}{c}\text { Prevalance } \\
\%(\mathbf{N})\end{array}$ & $\begin{array}{c}\text { Attendance related } \\
\%(\mathbf{N})\end{array}$ & $\begin{array}{c}\text { SDS+ } \\
\%(\mathbf{N})\end{array}$ & $\begin{array}{c}\text { Accepted help } \\
\%(\mathbf{N})\end{array}$ & $\begin{array}{c}\text { Would attend } \\
\%(\mathbf{N})\end{array}$ \\
\hline Alcohol (hazardous) & $28.0(183)$ & $18.6(34)$ & $24.6(45)$ & $14.2(26)$ & $84.6(22)$ \\
Cigarettes & $13.8(90)$ & $4.4(4)$ & $35.6(32)$ & $38.9(35)$ & $91.4(32)$ \\
Cannabis & $5.3(35)$ & $8.6(3)$ & $54.3(19)$ & $40.0(14)$ & $100.0(14)$ \\
\hline
\end{tabular}




\section{Authors' contributions}

$\mathrm{RP}, \mathrm{FK}$ and $\mathrm{MB}$ designed the study and helped to draft the final manuscript. MB facilitated data collection. RP was responsible for data analysis. All authors read and approved the final manuscript.

\section{Acknowledgements}

This study was funded by a grant from Lambeth Primary Care Trust.

\section{References}

I. Liebschutz JM, Finley EP, Braslins PG, Christiansen D, Horton NJ, Samet JH: Screening for sexually transmitted infections in substance abuse treatment programs. Drug and Alcohol Dependence 2003, 70:93-9.

2. Hwang LY, Ross MW, Zack C, Bull L, Rickman K, Holleman M: Prevalence of sexually transmitted infections and associated risk factors among populations of drug abusers. Clinical Infectious Diseases 2000, $31: 920-6$.

3. Lally MA, Alvarez S, Macnevin R, Cenedella C, Dispigno M, Harwell Jl, Pugatch D, Flanigan TP: Acceptability of sexually transmitted infection screening among women in short-term substance abuse treatment. Sexually Transmitted Diseases 2002, 29:752-5.

4. Marx R, Aral SO, Rolfs RT, Sterk CE, Kahn JG: Crack, sex and STD. Sexually Transmitted Infection 199I, 18:92-10I.

5. Crawford M, Lowe PC, Greene L, Brookings C: The prevalence of excessive alcohol consumption and the acceptability of brief advice in a sexual health clinic: cross sectional survey. Sexually Transmitted Infection 2004, 80:416-7.

6. Rashad I, Kaestner R: Teenage sex, drugs and alcohol use: problems identifying the cause of risky behaviours. Journal of Health Economics 2004, 23:493-503.

7. Patton R, Hilton C, Crawford MJ, Touquet R: The Paddington Alcohol Test: A Short Report. Alcohol \& Alcoholism 2004, 39:266-8.

8. Gossop M, Darke S, Griffiths P, Hando J, Powis B, Hall W, Strang J: The Severity of Dependence Scale (SDS): psychometric properties of the SDS in English and Australian samples of heroin, cocaine and amphetamine users. Addiction 1995, 90:607-I4.

9. Martin G, Copeland J, Gates P, Gilmour S: The Severity of Dependence Scale (SDS) in an adolescent population of cannabis users: Reliability, Validity and Diagnostic Cut Off. Drug and Alcohol Dependence 2003, 83(I):90-93.

10. Crawford MJ, Patton R, Touquet R, Drummond DC, Byford S, Barrett B, Reece B, Brown A, Henry JA: Screening and referral for brief intervention of alcohol misusing patients in an Accident and Emergency Department: A pragmatic randomised controlled trial. The Lancet 2004, 364:1334-9.

II. Coulthard M, Farrell M, Singleton N, Meltzer H: Tobacco, Alcohol and drug use and mental health London: Stationery Office; 2002.
Publish with Biomed Central and every scientist can read your work free of charge

"BioMed Central will be the most significant development for disseminating the results of biomedical research in our lifetime. "

Sir Paul Nurse, Cancer Research UK

Your research papers will be:

- available free of charge to the entire biomedical community

- peer reviewed and published immediately upon acceptance

- cited in PubMed and archived on PubMed Central

- yours - you keep the copyright

Submit your manuscript here:

http://www.biomedcentral.com/info/publishing_adv.asp
BiolMedcentral 